\title{
MIEDO A LA ORDEN INFLUENCIAS DE LO EXTRAÑO EN LAS NARRATIVAS SERIADAS
}

Ariel Gómez Ponce (Universidad Nacional de Córdoba)

Recebido em 10 mai 2020. Aprovado em 18 jun 2020.
Ariel Gómez Ponce es Doctor en Semiótica; Profesor en Español como Lengua Materna y Lengua Extranjera (Universidad Nacional de Córdoba), y cuenta con un Posdoctorado en Ciencias Sociales (CEA, FCS, Universidad Nacional de Córdoba). Actualmente, es Coordinador Académico de la Maestría en Relaciones Intrnacionales, Profesor Asistente en las asignaturas Sociología Sistemática y Procesos Políticos Internacionales (Lic. En Ciencias Políticas, Facultad de Ciencias Sociales, UNC) y es Becario Posdoctoral CONICET. En reuniones científicas, como también en artículos y en cursos de grado y posgrado, se aboca al análisis de series televisivas desde la perspectiva de la semiótica de la cultura (Lotman, Bakhtin) y los estudios culturales (Jameson), problematizando el modo en que estas narrativas ponen en cuestión las identidades y los modos culturales del sentir.

Email: arielgomezponce@unc.edu.ar

ORCID iD: https://orcid.org/0000-0001-8830-9544

Resumen: El artículo estudia lo extraño como operación de sentido que traza puentes entre lo insólito sobrenatural y la narrativa policial de misterio (TODOROV, 1994), al tiempo que revela signos epocales por cuanto se alimenta de las 
anomalías que toma de los imaginarios sociales (ARÁN, 2009; CAMPRA, 2008). Recupero los aportes de Fredric Jameson ([1992] 1989; 2007), para quien el extrañamiento ejerce una fuerza crítica $y$, en su intervención, señala aquello que los sistemas culturales interpretan como "lo natural". Propongo a este efecto de sentido como un rasgo formante de series televisivas que pretenden escenificar la impronta del miedo, disolviéndola en diferentes formas genéricas. Para dar cuenta de esta inclinación, analizaré una narrativa animada como Scooby-Doo, serie señera que, por su intensa inscripción en la memoria cultural y su impronta en la cultura popular, ofrece claves de interés para reflexionar acerca de lo extraño como un lugar de enunciación. El contraste entre dos versiones de esta franquicia (1969-1970 y 2010-2012) me permitirá poner de manifiesto una tradición en donde la extrañeza, aunque materializando los efectos psicológicos del miedo y el desconcierto, se ha vuelto una explicación más tranquilizadora que una realidad contemporánea, en donde se ha instalado una perturbación sostenida en las subjetividades.

Palabras claves: Series televisivas; Extrañamiento; Miedo; Cultura popular; Insólito ficcional.

Resumo: O artigo estuda o estranho como uma operação de significado que cria pontes entre insólito e narrativas de mistério policial (TODOROV, 1994), enquanto revela sinais de época, pois se alimenta das anomalias que ele tira do imaginário social (ARÁN, 2009; CAMPRA, 2008). Resgatarei as contribuições de Fredric Jameson ([1992] 1989; 2007), para quem o estranhamento exerce uma força crítica e, em sua intervenção, aponta o que os sistemas culturais interpretam como "o natural". Proponho esse efeito de significado como uma característica formativa das séries de televisão que buscam encenar a marca do medo, dissolvendo-o 
em diferentes formas genéricas. Para explicar essa inclinação, analisarei uma narrativa animada como Scooby-Doo, uma série histórica que, devido à sua intensa inscrição na memória cultural e à sua marca na cultura popular, oferece pistas interessantes para refletir sobre o estranho como lugar de enunciação. O contraste entre duas versões dessa franquia (19691970 e 2010-2012) permitirá destacar uma tradição em que o estranhamento, embora materialize os efeitos psicológicos do medo e da perplexidade, se tornou uma explicação mais tranquilizadora do que uma realidade contemporânea, onde um distúrbio foi instalado sustentado nas subjetividades.

Palavras-chave: Séries de televisão; Estranho; medo; Cultura popular; Fiç̧ão insólita.

\section{PALABRAS INICIALES}

Sin lugar a dudas, Scooby-Doo es una de las animaciones más emblemáticas del siglo XX. Producto de su época, logró, sin embargo, trascenderla e instalarse como una referencia casi obligada de la cultura pop. Sabido es que Scooby-Doo surge en la década de los 60s, durante el estallido de las técnicas de animación limitada, y poco después del éxito de Jonhy Quest (1964-1965), The Flintstones (1960-1966) y The Archie's Show (1968-1969), con las cuales el relato del perro detective mantiene cercanía estructural. Herederas de la tradición folletinesca, y coetáneas de las sit-coms de posguerra, todas estas animaciones abonan ese prolífico fenómeno que, en tiempos recientes, reconocemos genéricamente como una "serie televisiva"

1 Aún consciente de la especificidad del lenguaje de las series animadas (también conocidas como dibujos animados), en este artículo, opto por englobarlas dentro de aquello que Robert Allen (2001) define como una serialización: término genérico que pretende describir creaciones narrativas que, manteniendo sus reglas básicas de funcionamiento, han redimensionado la estructura "por entregas" de la literatura 


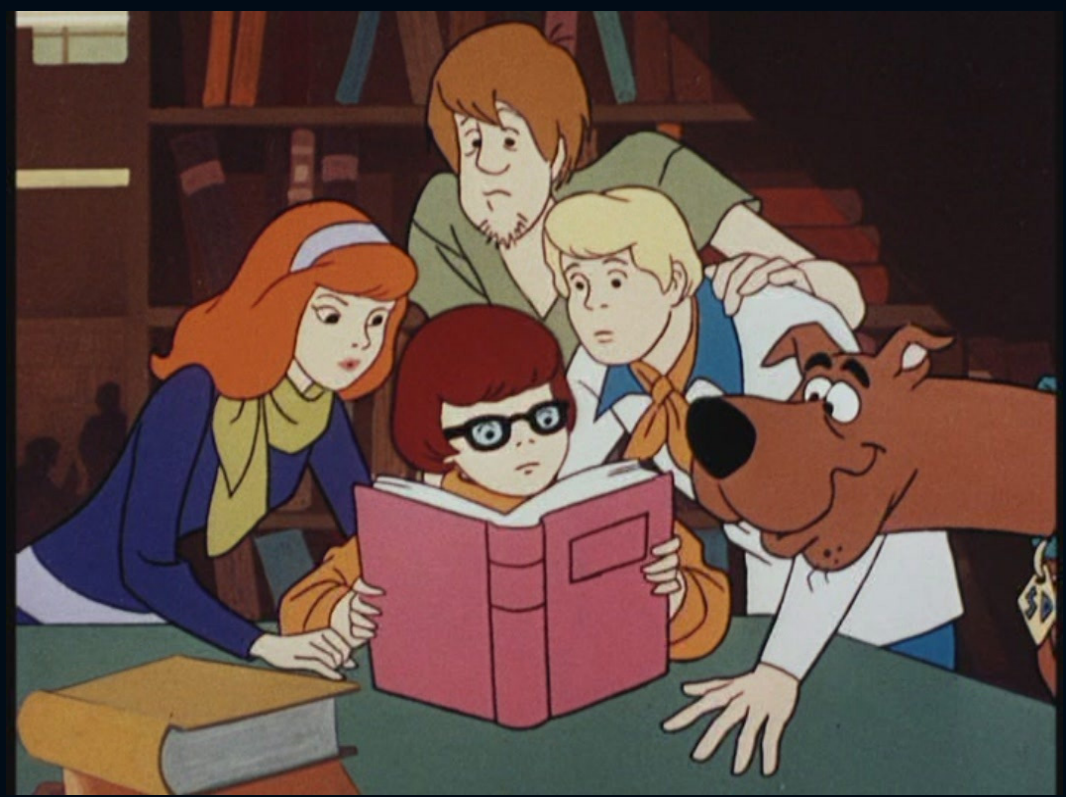

Figura 1

Scooby-Doo ejemplifica esas formas que trabajaban con un modelo simple que podía repetirse hasta el agotamiento: relatos breves que oscilaban los veinte minutos, con poco desarrollo de personajes y un esquema narrativo escueto, fácil de replicar episodio a episodio e, incluso, de trasladar a otros futuros productos. En este periodo, el público infantil se descubre como un fuerte nicho para un mercado televisivo y, bajo estas condiciones prolíficas, la productora Hanna-Barbera se instala como una auténtica fábrica que elaboró centenares de relatos que hoy se consideran de culto.

Durante décadas, la historia del perro detective fue el caballo de batallas de ese estudio de animación. Scooby-Doo, Where are you?

folletinesca. Esta postura no desconoce, tampoco, el potencial de las animaciones que, aunque puedan aparentar relatos llanos, reclaman un intento proceso cognitivo, en tanto deben traducir a un público infantil contenidos sociales de gran complejidad. Sobre esta última precisión, véase LOTMAN, 2000. 
(más conocida en habla hispana como Misterio a la orden) fue la primera serie de la franquicia y, aunque contó solo con 25 episodios, tuvo un inmenso impacto cultural que garantizó su permanencia aún en la actualidad. La historia se centraba en las aventuras de cuatro adolescentes y un gran danés, viajando en su camioneta Mystery Machine (la Máquina del Misterio) y resolviendo enigmas sobrenaturales a lo largo y ancho del país. Sin embargo, pese a su aparente simplicidad, Scooby-Doo mostraba un juego incesante de tradiciones, en donde lo insólito sobrenatural se montaba sobre una estructura policial de misterios, ello sin perder una enorme cuota de humor.

Por su permanencia en el tiempo, y por este trabajo creativo con distintas matrices genéricas, me parece oportuno volver sobre esta narrativa icónica que marcó un sendero en las series televisivas hoy consumidas. Producida a la medida de sus espectadoras y espectadores, el estudio de una serie animada como Scooby-Doo debe enmarcarse en el de aquellas narrativas que, bajo la égida de los modos de producción mercantil, hacen de los géneros una instancia conflictiva. Creo, sin embargo, que una de las razones del éxito de Scooby-Doo estriba en su despliegue de lo extraño: factor que no solo pone en marcha las aventuras detectivescas y sostiene una intensa expresión de lo insólito, sino que también permite el retrato ficcional de los cambios de orden social a lo largo del tiempo.

De manera especial, me refiero a ese efecto de sentido que se reconoce como lo extraño, concepto largamente debatido en los estudios literarios y cinematográficos, consecuencia de su recurrencia insistente para escenificar formas de lo ominoso y de la incertidumbre. El presente artículo, en tal sentido, explora una 
premisa que he sugerido en mi trayecto de investigación (véase GÓMEZ PONCE, 2020), en donde me he interrogado por narraciones seriales que se apropian de lo extraño para escenificar la impronta del miedo, disolviéndola en diferentes formas genéricas. Se trata de productos masivos que no se interesan por definir y nombrar aquellos afectos que rondan el temor y la paranoia, sino antes bien construir un clima de ansiedad que movilice a las y los espectadores, algo que Scooby-Doo parece haber instalado tempranamente en el mercado televisivo.

Para dar cuenta de ello, un primer apartado estará dedicado a deslindar la categoría de lo extraño, con especial énfasis en la propuesta de Fredric Jameson, para quien este efecto de sentido pone en escena un ejercicio crítico, revelando los modos en que las culturas codifican su normalidad. Se trata de una problemática que la teoría narrativa de Jameson ([1992] 2007) ha afrontado, en un intento por elucidar las funciones cambiantes del arte en las sociedades y las formas que estas dinámicas adquieren en los derroteros históricos.

A la luz de este marco conceptual, retomaré la impronta de lo extraño en los imaginarios del insólito sobrenatural y del policial de misterio, como un rasgo formante que anuda ambas tradiciones. El resultado de esta lectura pretende explicar lo extraño como una compleja codificación semiótica a través de la cual la materialidad artística escenifica modos histórico-sociales de leer lo real. Sigo, entonces, la empresa de Jameson, para quien es menester "capturar la variedad de formas que puede adoptar" (2010, p.64) lo extraño, logrando que exprese su función histórica. 
Entiendo, no obstante, que esta definición se comprende acabadamente cuando se la percibe en su paso por el tiempo. Por ello, en un segundo apartado focalizaré en la primera versión de la franquicia: Scooby-Doo, Where are you?, emitida en 1969. Su descripción detallada habilitará una interpelación de lo extraño, como también de algunas características que, años más tarde, germinarán de manera estridente en las series televisivas. En el tercer apartado, analizaré Scooby-Doo! Mystery Incorporated, serie cuya complejidad argumental, cuarenta años después de la versión original, explora vacilaciones históricas de la adolescencia que se acompañan por múltiples crisis en las instituciones sociales. El contraste de ambos relatos pondrá de manifiesto una tradición en donde lo extraño, aunque materializando los efectos psicológicos del miedo y el desconcierto, se ha vuelto una explicación más tranquilizadora que la propia realidad, allí donde se ha instalado una perturbación sostenida en las subjetividades.

\section{SOBRE LO EXTRAÑO. UNA LECTURA TEÓRICA}

Se ha señalado insistentemente que fantástico y policial erigen sus sentidos en torno a una hipótesis que pretende explicar la realidad (TODOROV, 1994; ARÁN, 1999). Desde esta lectura, la postura de Rosalba Campra (2008, p.121) es bastante ejemplar, por cuanto señala que ambas formas trabajan "una explicación que reintroduce un orden en la incomprensibilidad del mundo": una inclinación que define como el intento por colmar un silencio, que también las y los lectores buscan recomponer al concluir la historia. Se trata de un rasgo formante común que, empero, fracasa en el fantástico por una imposibilidad de llegar a la verdad (ARÁN, 2009). 
Porque, si bien el enigma es un factor desencadenante que mueve la acción, la diferencia estriba en el modo en que se resuelve esta ausencia: lo que en las narraciones policiales es un misterio cuyo esclarecimiento se alcanza mediante una investigación, en aquellas fantásticas aparece, más bien, como un vacío de la razón, o bien una develación contradictoria. Y, mientras en el primero priman los avatares para la resolución del enigma, el segundo pone en el acento en las reacciones que provoca dicha solución (TODOROV, 1994), aunque, en conjunto, ambas pongan de manifiesto "las posibilidades que ofrece el misterio, es decir, lo secreto, lo que no se manifiesta [...] lo que solamente permite ser contemplado en sus bordes" (TEOBALDI, 2009, p.67).

Indefectiblemente, fantástico y policial introducen un problema sobre la verosimilitud, que se codifica de modo diferente según los regímenes que imponen cada una de estas tradiciones genéricas. $Y$ aunque no pretendo extremar las semejanzas entre estos géneros, en este artículo me intereso por profundizar en una operación de sentido compartida, la cual se hace especialmente visible en el fantástico vinculado a experiencias de lo sobrenatural con el policial de enigma o misterio, dada la proximidad estructural entre ambas formas (TODOROV, 1992). Me refiero a ese mecanismo que Tzvetan Todorov asimila a lo extraño, eficaz para la creación de suspenso y para el sostenimiento de un orden de lo inquietante, en tanto su función radica en "la descripción de ciertas reacciones, en particular, la del miedo" (1994, p.41).

Como es sabido, esta concepción se hereda de las discusiones relativas a ese recurso propio del arte que el formalismo ruso llamó extrañamiento o ostranenie (desfamiliarización) (SHKLOVSKI, 
[1917] 2011). En su trabajo sobre las narrativas fantásticas, la categoría se ajusta a lo no-familiar, en un sentido caro a lo ominoso (das umheimliche) de Freud, por cuanto explica una impresión de extrañeza y a un problema de ambigüedad: en otras palabras, a la aparición de elementos de la realidad cotidiana y normal que no están alterados, pero que tampoco justifican su presencia. A medida que este fenómeno asedia y se torna cada más indiscernible, el miedo y la ansiedad crecen en las y los espectadores. El extrañamiento despierta, como piensa Rosalba Campra (2008, p.133), la sospecha de que se ha producido una fisura en la realidad o, para ser más exacto, la emergencia de una "realidad perturbante".

Aquí parece oportuno recuperar la propuesta de Fredric Jameson (2010), para quien el extrañamiento ejerce una fuerza crítica, pues devela marcas ideológicas ocultas en aquello que las culturas han interpretado como la "normalidad". En esta lectura, Jameson recupera (sin desconocer la tradición formalista) los aportes de Bertolt Brecht, como también el estudio de las mitologías barthesianas (BARTHES, [1957] 2010), para proponer lo extraño como una operación crítica que permite "subrayar una artificialidad" (JAMESON, 2010, p.66). Para el filósofo marxista, la intervención de lo extraño muestra el modo en que lo familiar y lo habitual han sido interpretados como "lo natural" en los sistemas culturales y, por ello, sostiene que "hacer que algo nos parezca extraño, y por lo tanto nos obligue a mirarlo con nuevos ojos, implica la precedencia de una familiaridad general, de un hábito que nos impide mirar las cosas tal como son, una suerte de adormecimiento de la percepción" (2010, p.64) 
En buena medida, recupero esta precisión de Jameson, para sostener que el extrañamiento entraña un proceso de reconocimiento sobre una realidad que se ha vuelto inasequible, compleja en demasía y, por ende, de ardua descripción. Me refiero a cambios en las experiencias históricas y en los imaginarios sociales que, sin embargo, persiguen alguna forma de asimilación e interpretación estética, premisa que debe pensarse a la luz de una las hipótesis más insistentes en Jameson: el arte repone soluciones imaginarias ante las contradicciones culturales; la historia, por su parte, es una causa ausente $y$, dado que solo es accesible en forma textual, su restauración debe ser el último horizonte interpretativo (JAMESON, 1989, p.17-30).

Aquí no debe olvidarse, tampoco, que las narrativas insólitas son un terreno aún más fértil para esta empresa, por tanto se alimentan de las anomalías que toman de los imaginarios. Como de modo insistente ha sugerido Pampa Arán, ellas trabajan con las rasgaduras que se producen en la trama social, porque es esta la función semiótica de lo insólito: "interrogar(se) acerca de los modos y rupturas del orden natural y social en prácticas cotidianas" (2009, p.18). Al amparo de estas lecturas, lo que me propongo, entonces, es repensar lo extraño como una compleja codificación semiótica a través de la cual la materialidad artística escenifica modos histórico-sociales de leer lo real.

Por su aparente simplicidad narrativa y su persistencia temporal, Scooby-Doo funciona para explorar, sin pretensiones de abarcar una totalidad, este ejercicio crítico del extrañamiento. Intuyo, sin embargo, que esta inclinación se hace visible más acabadamente cuando se la percibe en el paso del tiempo, y a la 
luz de cambios históricos. Por tal motivo, primero me abocaré a emprender una descripción detallada sobre la manera en que en la ficción de 1969 introduce lo extraño, instalándolo en una tradición que será interpelada, luego, por la narrativa de 2010, sobre la cual profundizaré en un segundo momento.

Cierro este rastreo teórico, recordando que, lejos del habitual desdén hacia las narrativas de consumo, la teoría narrativa jamesoniana mantiene un interés activo por los productos de la cultura de masas: complejos laboratorios que permiten diagnosticar las contradicciones históricas, incluso antes de que la sociedad pueda nominarlas y tomar consciencia de ellas. Esta premisa se conservará viva en mi recorrido por la franquicia de Scooby-Doo, con especial énfasis en las dos de las series que analizaré como casos paradigmáticos: Scooby-Doo, Where Are You? (Scooby-Doo, ¿Dónde estás tú?) (CBS, 1969-1970) y ScoobyDoo! Mystery Incorporated (iScooby-Doo! Misterios S.A.) (Cartoon Network, 2010-2013).

Asimismo, exploraré los textos en una doble dirección, interrogándome por cómo resuelven lo extraño mediante algunos signos epocales que irrumpen en las ficciones, y por cómo atraviesa formas estéticas como el fantástico y el policial, en tanto rasgo distintivo. Y, aunque pueda pensarse que hoy estas clasificaciones genéricas han perdido validez (por ese afán posmoderno, cuya sed de innovación y novedad hace de la experimentación una ley), junto a Fredric Jameson, entiendo que estas tradiciones sobreviven y mutan dentro del mercado, allí donde aseguran un contrato de lectura y, con ello, una adecuada recepción en su público (ARÁN, 1996). 


\section{LO EXTRAÑO EN SCOOBY-DOO, WHERE ARE YOU?}

Comienzo recuperando la primera versión de la franquicia Scooby-Doo, emitida por la cadena de broadcasting CBS y estrenada el 13 de septiembre de 1969. Interesa recordar que la serie animada surge como una apuesta de la entonces reciente productora Hanna-Barbera (integrada por los exdirectores de la Metro-Goldwyn-Mayer, William Hanna y Joseph Barbera) con el fin de cubrir la franja matutina de los sábados y adaptar contenidos infantiles para la pantalla televisiva. En primera instancia, la serie se planifica como una sit-com musical, centrada en los avatares de un grupo de adolescentes, en un estilo caro a The Archie's Show cuyo éxito (televisivo y discográfico) pretendía replicarse (PERLMUTTER, 2019). La idea se descarta rápidamente para, en su lugar, componer una historia de terror que convoque a niñas y niños, aunque sin aterrorizarles (BIRD, 2018).

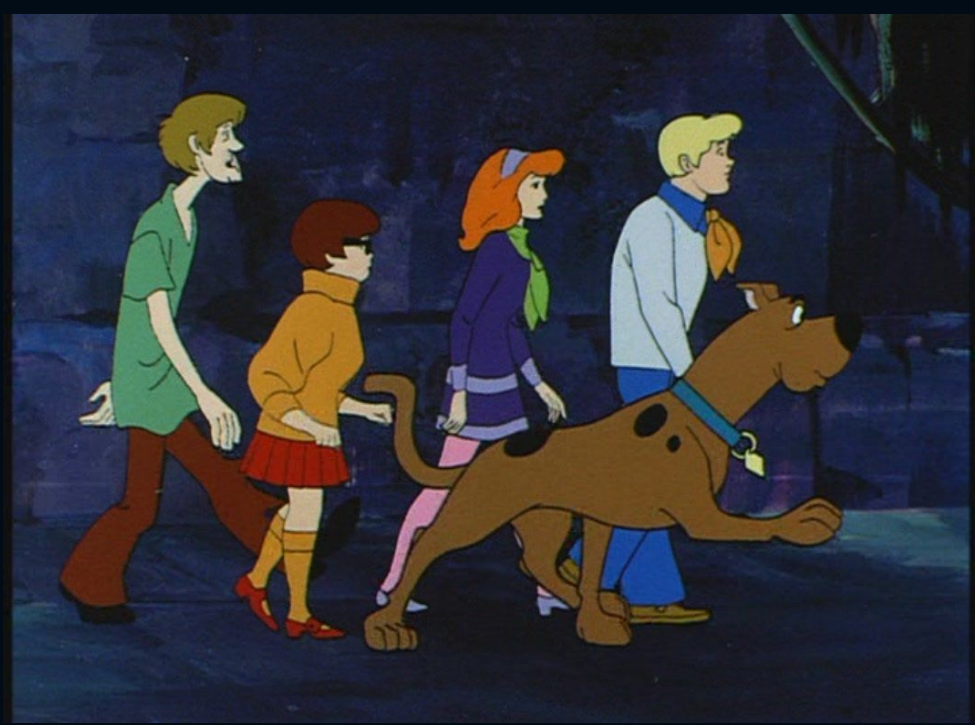

Figura 2 
Nace, entonces, Scooby-Doo, Where are you?: un relato afable que contará la historia de cuatro adolescentes y su perro, en la búsqueda de misterios por resolver. La maquinaria que desata las intrigas es, casualmente, un factor sobrenatural, componiendo así un relato versátil, pero de compleja inscripción genérica, por cuanto muestra la primacía de una estructura de policial de misterio que es atravesada por un fuerte componente cómico. Sin intención de extremar semejanzas, esta búsqueda de la verdad podría ser definida en términos de lo que Todorov (1994, p.45) llamó un "fantástico explicado", cuyo máximo exponente se encuentra en John Dickson Carr (1906-1977). Y, como en las obras de este escritor estadounidense, la función de las y los detectives en ScoobyDoo, Where are you? es volver nítido un misterio que "evoca" lo sobrenatural, revelando los artilugios de un criminal que hace uso de la monstruosidad "con el fin de complicar el asunto y desviar las sospechas" (TODOROV, 1994, p.44).

Para construir este heterogéneo encuadre genérico, la ficción explotó elementos paródicos de las sit-coms familiares y de las animaciones de la época, reforzando algunas características que, tiempos después, serán propias de la serie como género cultural. En particular, me refiero a esa forma reconocida como "evil of the week": ello es, la presentación de un nuevo villano a vencer en cada episodio, logrando que los capítulos sean relativamente independientes entre sí, sin componer un hilo narrativo que dé coherencia a la totalidad de la temporada (véase GÓMEZ PONCE, 2018) $)^{2}$. En efecto, este rasgo permite percibir una redundancia en

2 Esta particularidad tuvo gran pregnancia, inspirando incluso a narrativas más recientes como Supernatural (The CW, 2015-2020), Grimm (NBC, 2011-2017) e, incluso, Buffy, The Vampire Slayer (Warner Channel, 1997-2003) (serie esta que, en un claro guiño 
las tramas que facilitaba la conversión de la información en loci comuni, garantizando una rápida adecuación a la narrativa, como también su traslado a nuevos productos que pudieran realizarse (recuérdese, por ejemplo, otro éxito coetáneo como Jossie and the Pussycats).

La estructura resultante, repetida episodio a episodio, puede sintetizarse de la siguiente manera: i) de casualidad ("nos hemos tropezado con otro misterio", dirán las y los jóvenes, T01 E12) ${ }^{3}$, el equipo se encuentra con alguna situación enigmática sobre la que arrojar luz; ii) rápidamente, el misterio se vincula a una entidad monstruosa o fantasmagórica que los atemoriza; iii) son perseguidos por este ser, y se separan para rastrear pistas en un paulatino y lento proceso de develación; iv) comienzan a darle caza a la entidad y elaboran planes rebuscados que fracasan; y v) por obra del azar, capturan a la entidad y desenmascaran los propósitos del criminal, quien (con alguna variante) protesta: "lo habría conseguido, de no ser por esos chicos entrometidos y su perro".

Scooby-Doo, Where are you? trabajaba, además, con imágenes fácilmente reconocibles para el público infantil, y cada protagonista modelizaba un carácter bien diferenciado: acompañando a ese perro temeroso que despertaba inocencia, estaban el audaz líder (Fred), la glamorosa (Daphne), el distraído (Shaggy) y la intelectual y voz de la razón (Vilma). Y si bien es cierto que la serie reforzaba estereotipos en cuanto a prácticas sociosexuales e identidades racionales, no se debe olvidar que, en un periodo dominado casi

intertextual, define como "Scooby Gang" al grupo de adolescentes protagónicos). Sobre el evil of the week, véase GÓMEZ PONCE, 2018.

3 Todas las traducciones me pertenecen. Asimismo, la codificación para referenciar las series remite al número de temporada (por ejemplo, T01) y de episodio (por ejemplo, E02). 
exclusivamente por personajes zoomorfos (Yogi Bear, Huckleberry Hound, Quick Draw McGraw) o varones justicieros (Space Ghost, Jonny Quest, Birdman), Scooby-Doo, Where are you? desplegaba cierta heterogeneidad para un público más amplio (incluso, un público adulto), al tiempo que se alejaba de los formatos redundantes en violencia bastante recurrentes por aquellos años (como es el caso, por ejemplo, de la exitosa Tom and Jerry).

En conjunto, la pandilla detectivesca estaba dotada de rasgos que permitian una identificación positiva: eran jóvenes que sentían un deber moral y, sin que nadie los incitara, afirmaban que "tendremos que resolver este misterio" (T01, E01). Frente a los conflictos, colaboraban con la policía e, incluso, resolvían las fechorías antes de que las fuerzas del orden lograran intervenir. En contraposición, se hallaban estas monstruosidades de distinta índole, bajo cuyo disfraz aparecían ladrones de delitos no violentos, usualmente vinculados a la estafa y la falsificación. Lo interesante, empero, es que esta confrontación daba cuenta de valores axiológicos claramente definidos, inclinación que coincide con una de las hipótesis de Jameson ([1992] 2007), para quien las producciones masivas de este periodo tendían a reforzar las divisiones maniqueas, tal vez porque el contexto de la Guerra Fría y su proliferación de enemigos inocuos reclamaba la elaboración de categorías absolutas. 


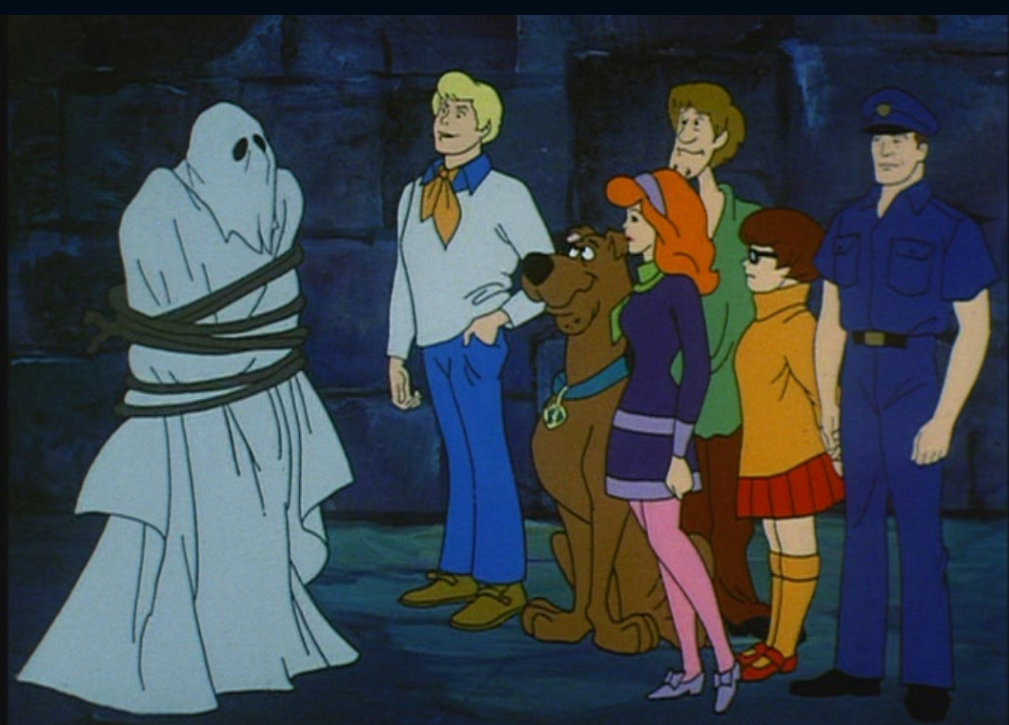

Figura 3

Para reforzar este distanciamiento, los villanos de la serie animada incurrían en formas estereotipadas, sirviéndose de figuras que, aunque de larga tradición, denotaban también una clara influencia del cine comercial de la época: monstruos, alienígenas, brujas, demonios, fantasmas, vampiros, zombies y momias son claros ejemplos de las atrocidades que habitan los episodios de la serie. El relato tiende a detenerse para introducir alguna leyenda de amplia circulación en los imaginarios y, en su despliegue, anidaban claves para que las y los espectadores contextualicen las historias colmadas de casas abandonadas, castillos tenebrosos, pantanos y bosques lóbregos.

Precisamente, un hilo conductor fuerte para entender los efectos de sentido en esta serie yace en la composición estos sus ambientes lúgubres. Porque Scooby-Doo, Where are you? expande 
los efectos de la ambientación propia del gótico, desplazándolos hacia lugares cotidianos, ahora perturbadores. Es algo que ya se introduce en el primer episodio (T01 E01), cuando la pandilla de detectives se enfrenta a un caballero fantasmal en un museo, lugar educativo y de dispersión que pasa, no obstante, a inspirar temor. Con sus variantes, las historias se recortan contra el fondo de estos espacios que se vuelven truculentos: una playa donde los jóvenes se esparcen, arribando a la luz de la luna (T01 E02); un parque de atracciones con sus carruseles en movimiento y sus juegos encendidos que, sospechosamente vacío de gente, se percibe como "macabro" (T01 E08); un colorido y jocoso circo alejado de la ciudad, pero asediado por un payaso malévolo (T01 E10); o bien una ciudad desértica, con una marioneta que está, sin explicación alguna, sentada al borde de una calle poco iluminada (T01 E09).

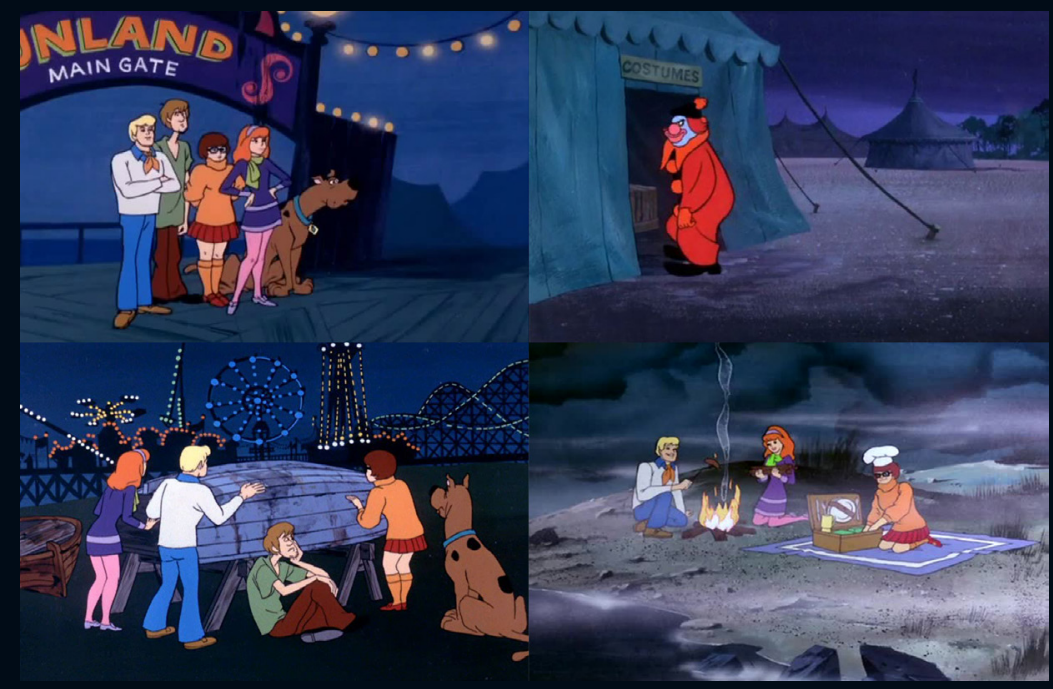

Figura 4 
Hay una predilección constante por la noche, en donde resuenan chillidos de murciélagos, aullidos de lobos, el resquebrajar de árboles y el resoplido de vientos lejanos. Acorde a esta redundancia, la serie presenta protagonistas que, vestidos con sus colores vivaces y llamativos, desentonan con los tintes sombríos que trastocan un carnaval o un baile de graduación en lugares escalofriantes. Y, cuando se enfoca más de cerca, estos personajes quedan casi fuera de plano porque, incluso, parecen atemporales: son adolescentes que bailan, almuerzan, surfean, esquían y, en pocas palabras, se divierten en entornos familiares que, imprevisiblemente, se han vuelto perturbadores, traduciéndose así a los lenguajes truculentos del gótico y el terror.

A simple vista, puede pensarse que lo extraño se encarnaría en otros aspectos tal vez más obvios, como lo es el hecho de que Scooby-Doo dialogue con sus pares humanos y se haga comprender. Sin embargo, como bien advierte Guadalupe Campos (2010, p.34), no es necesario explicar que un perro articule lenguaje porque esta característica "pertenece a la naturaleza del sistema de causalidades de la serie que eso ocurra", formando parte de un contrato que, desde la primera escena, las y los espectadores aceptan. Lo que no está pautado, empero, es la conversión de los espacios habituales de la juventud (al menos, de los años 60s) en enclaves de lo ominoso. Y si bien podría conjeturarse que, cuando la explicación racional aparece, el carácter insólito del relato se disuelve, ciertas esquirlas de sentido permanecen en una dimensión espacio-temporal que afecta el modo en que la pandilla se apropia de su realidad: "todo aquí es muy extraño y parece no tener sentido", afirmarán (T01 E10). 
Por ello, a mi entender, los efectos de lo extraño se resuelven en todo su esplendor, mediante un layout que se proyecta sobre la totalidad de la serie animada: ello es, una estética de lo nofamiliar, sostenida a través de procedimientos de representación que atañen a las expresiones espacio-temporales, forjadas por un caudal de elementos perceptivos como la coloración de los fotogramas o bien el acompañamiento sonoro. En cierto modo, Scooby-Doo, Where are you? escenifica el miedo, y me pregunto si acaso no está anticipando una operación que es, por lo demás, recurrente en las series más actuales, más allá de su inscripción genérica. Pues, como he sugerido en otras indagaciones (GÓMEZ PONCE, 2020), en las apariciones de este afecto habría algo que excede las capacidades del lenguaje verbal que, no obstante, se hace visible en una atmósfera que los recursos audiovisuales se esmeran por recomponer, a través de imágenes de orden espacial y temporal.

En tal sentido, creo que, a través del ejemplo situado que ofrece esta animación infantil, lo extraño está dando cuenta de su eficacia para escenificar afectos que, de difícil descripción, perturban a las subjetividades: es este su ejercicio crítico. Demuestra, asimismo, su potencial como puente genérico, en tanto habilita continuidades y desvíos entre las estructuras del policial y las derivas sobrenaturales del fantástico, al tiempo que hace frontera con las formas del absurdo. Como se verá en el siguiente apartado, comienza a mostrar que su pertinencia puede ir más allá de las lecturas tradicionales que lo asocian al insólito, para descubrirlo como un mecanismo que monta los efectos psicológicos del miedo, a través de desequilibrios en los modelos 
de mundo propuestos, expresando así "la irresoluble falta de nexos entre los elementos de la pura realidad" (CAMPRA, 2008, p.136).

Por lo demás, es notorio que, hacia el final de la primera temporada ( $y$, con mayor énfasis, durante el desarrollo de la segunda en 1970) Scooby-Doo, Where are you? extreme sus propios rasgos. Se reforzará, entonces, la veta cómica: aumentan los gags visuales, se añaden risas grabadas como trasfondo de las acciones, y las escenas de persecución, ahora más jocosas, están acompañadas por alegres canciones. Pero, también, el arco argumental tiende hacia una complejización que recurre a la inclusión de flashbacks y que, también, le brinda más relevancia a ese método de investigación para la resolución de casos que, en los inicios, parecía más difuso. Al concluir la temporada, los personajes de ScoobyDoo se autodefinen ya como una "banda resuelve-misterios", y la serie cuenta con una fórmula narrativa consolidada y un cúmulo de formas redundantes que, al menos con algunas modificaciones interesantes, se repetirán durante medio siglo. Sobre esta cuestión, quisiera detenerme a continuación.

\section{SCOOBY-DOO! MYSTERY INCORPORATED. UNA REINVENCIÓN DE LO EXTRAÑO}

En el transcurso de cincuenta años, la franquicia conquistó innumerables dimensiones del mercado, produciendo no solo cientos de series y películas sino, además, un caudal de videojuegos en diferentes plataformas, juguetes de todo tipo y hasta una propia línea de ropa. Forzó su propia continuidad a través del diálogo con otras series animadas exitosas (Batman \& Robin, Charlie's Angel, Johnny Bravo), de la participación de celebridades (Cher y Sonny, 
o, más recientemente, el grupo Kiss y el actor John Cena), de la adaptación al lenguaje live-action (Scooby-Doo de 2002 y ScoobyDoo 2: Monsters Unleashed de 2004), o bien del retorno a los orígenes (tal es el caso de la exitosa a A Pup Named Scooby-Doo de 1988 y del filme a estrenarse durante 2020, centrados ambos en la infancia de la pandilla).

Scooby-Doo comenzó a agotar su propio relato, forjándose como un producto que se parodia a sí mismo. A ello debe añadirse que ese dinámico público infantil no solo se enfrenta hoy a una pantalla televisiva atiborrada de novedades que se elaboran a caudales, sino que, además, la cultura popular ha incorporado los derroteros de Scooby-Doo a su memoria, transformando a toda su mitología en un lugar común. Sin embargo, creo que, en una de sus series más recientes, anidan claves de interés para interpelar los derroteros de esa extrañeza que le permitió a Scooby-Doo, Where are you? instalarse en los umbrales del misterio y lo sobrenatural.

Se trata de Scooby-Doo! Mystery Incorporated, relato emitido entre 2010 y 2013, por Cartoon Network (cadena que, desde 1998, tendrá la exclusividad de la franquicia). Elogiada por la crítica y nominada en distintos galardones de animación infantil, la serie destaca por su estética singular y su complejidad argumental, en donde afloran un humor más irónico y diálogos profundos, tomando la forma de un drama televisivo contemporáneo, pero montado mediante técnicas de animación digital.

La historia de Scooby-Doo! Mystery Incorporated cuenta una transición hacia la adultez que, asimismo, alegoriza numerosos conflictos de estos adolescentes, inmersos en una sociedad de 
consumo. Se trata de un movimiento vertiginoso en relación a productos anteriores, por cuanto brinda una caracterización detallada de esta pandilla de detectives y de sus vínculos interpersonales. Si en la ficción de 1969 la persecución de pistas y fantasmas permitía la incorporación de una cuota de humor, aquí interviene un fuerte discurso amoroso: se refuerza la relación entre Fred y Vilma, pero principalmente en Shaggy y Vilma, dos personajes sobre quienes se especuló largamente sobre un romance, aunque las versiones anteriores decidieron omitirlo de manera deliberada.

Pese a ello, Scooby-Doo! Mystery Incorporated no deja de anclarse en toda una tradición. La estética pop se mantiene y la clásica Mystery Machine aún exhibe sus formas psicodélicas y su estilo flower power, replicando, casi sin intervención alguna, aquel vehículo presentado en 1969. Sin embargo, las vestimentas (casi inmutables durante cuarenta años) cambian de episodio a episodio, contextualizándose a las situaciones vividas por los personajes. La búsqueda de pistas, la planificación de las trampas y la resolución por las vías del azar también permanecen. Pero las persecuciones son menos coreografiadas, lo que permite un desarrollo más realista que se acerca a los formatos detectivescossobrenaturales de otras series del momento como Supernatural (2005-2020) o The Vampire Diaries (2009-2017). 


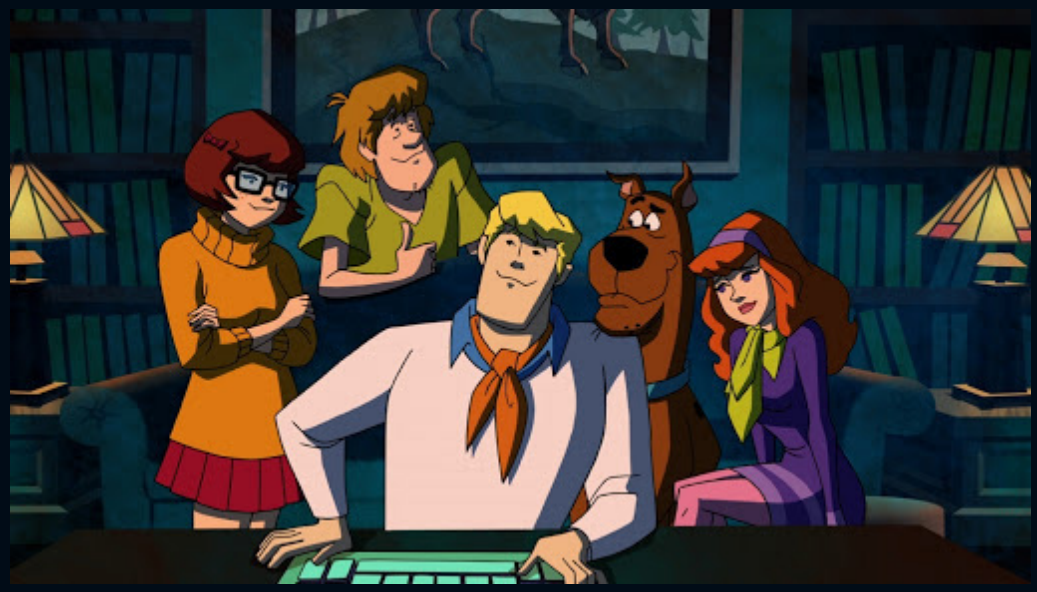

Figura 5

En este último sentido, dialoga activamente con el cine de terror de la época. Son constantes los guiños a películas icónicas como The Shining (1980), Gremlins (1984), Saw (2004), Paranormal Activity (2007) o Twlight (2008), pero también a la propia historia de la franquicia, rememorando con detalle casi obsesivo los monstruos que reinaron en la primera serie, y que ahora se conservan como piezas de un museo abocado a lo paranormal. Scooby-Doo! Mystery Incorporated reclama, por ende, un gran conocimiento de las narrativas previas, sin el cual no es posible comprender cabalmente las innumerables referencias aludidas. En tal sentido, se ha convertido en una enciclopedia de la cultura popular en cuyo centro están también germinando semillas que la propia ficción, a lo largo de sus cincuenta años, ha sembrado y abonado. 


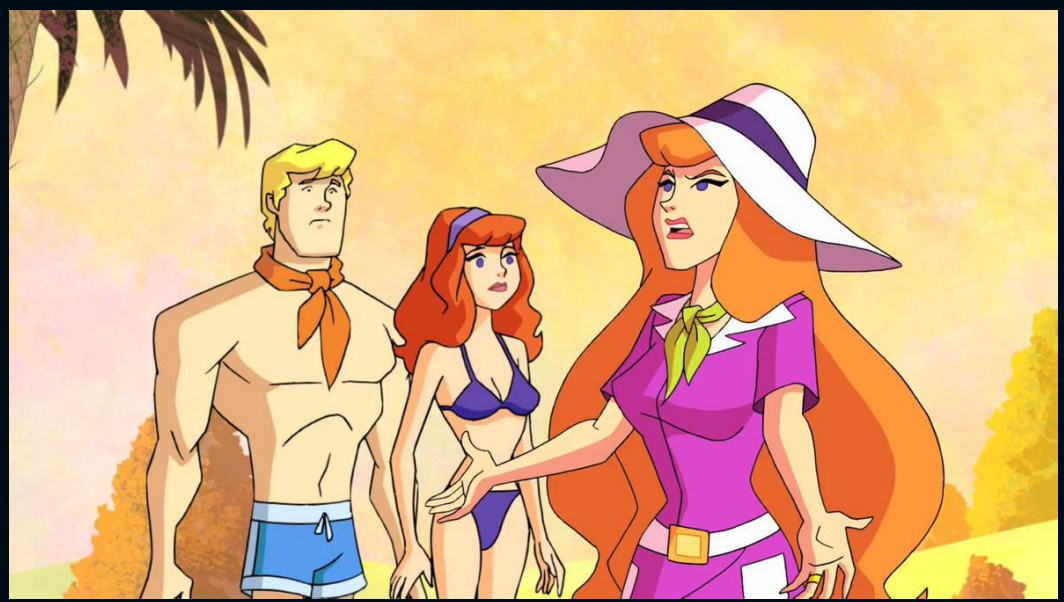

Figura 6

El argumento se desarrolla en la ciudad Cueva de Cristal, poblado que se autodefine como "el lugar más embrujado de la tierra" por ser un centro de actividad paranormal. Aquel vagabundeo casi errático de los personajes se detiene, y la pandilla afrontará la misión de develar estos fenómenos en su ciudad natal, en el marco de una pequeña empresa que han fundado, y de la cual proviene el título de esta serie: Misterios Sociedad Anónima.

Importa señalar que la ficción expande y perfecciona aquella característica que pusiera marcha el relato de 1969, convirtiendo a este entorno reconocible de lo urbano en una extrañeza inquietante que, por momentos, se torna terrorífica. Cueva de Cristal recibe la visita de numerosas entidades irracionales que la azotan a diario, aunque algún personaje dirá, sin escandalizarse, que "acabo de salir del hospital a causa del ataque de un monstruo" (T02 E09). Puede parecer banal, pero la expresión citada sintetiza cómo, en esta narrativa, no hay conflicto ante la presencia de entes diabólicos. Por el contrario, en Cueva de 
Cristal, lo inquietante yace en pasar unas vacaciones apacibles o deambular por la noche en tranquilidad, sin sufrir el asedio de alguna entidad paranormal.

Lo que sí despierta atención es que las porristas formen amistad con los jugadores de ajedrez, o que la chica más bella se enamore del freak, porque la unión de "populares" y "perdedores" rompe un orden que se presume lógico en la sociabilización escolar (T01 E16). Por lo cual, más que en la intervención de un monstruo devorador de niños, la extrañeza radica en el desbarate de ese reglado sistema social adolescente que lleva a la pandilla a interrogarse si no son estos los "misterios más grandes que hayamos enfrentado" (T02 E09). Esta variación no debe sorprender: una vez convertida la franquicia en formato estandarizado ( $y$, por ende, predecible), se torna arduo pensar en la pervivencia de la misma extrañeza que, cincuenta años atrás, Scooby-Doo, Where are you? instalara. Como advierte Rosalba Campra (2008), cuando la capacidad de lo extraño parece desgastarse, su afán por generar "roturas" de la realidad se abre paso en contenidos no necesariamente insólitos. En tal sentido, la reciente versión escenifica un mundo que "puede ser enteramente natural, inscribirse en un sistema de realidad identificable, y sin embargo escapar a la comprensión" (CAMPRA, 2008, p.136).

Contra el fondo de estas situaciones, lo extraño ejercita la crítica que señalara Jameson, develando lo que esta ficción entiende como lo "normal". Lo monstruoso y lo fantasmagórico se han naturalizado en esta narrativa, dando paso a una atmósfera de extrañeza perpetua. Porque, pese a que todas las situaciones paranormales concluyen en fraudes, quienes mueven los hilos de los misterios se sirven de la magia o de los hechizos, cubriendo 
con un manto sobrenatural a Cueva de Cristal: algunos embrujan la población (T01 E16) o la convierten en zombies (T01 E01), mientras otros transforman los niños en demonios (T01 E05) y a los animales en posesos (T02 E 17), o bien invocan espíritus macabros (T01 E23). Los hogares abundan en maldiciones (T01 E17) y la urbe entera es hostigada por los espectros de españoles colonizadores quienes, siglos atrás, fundaron la ciudad. Lo que en Scooby-Doo, Where are you? era extrañeza, en Scooby-Doo! Mystery Incorporated deviene regla.

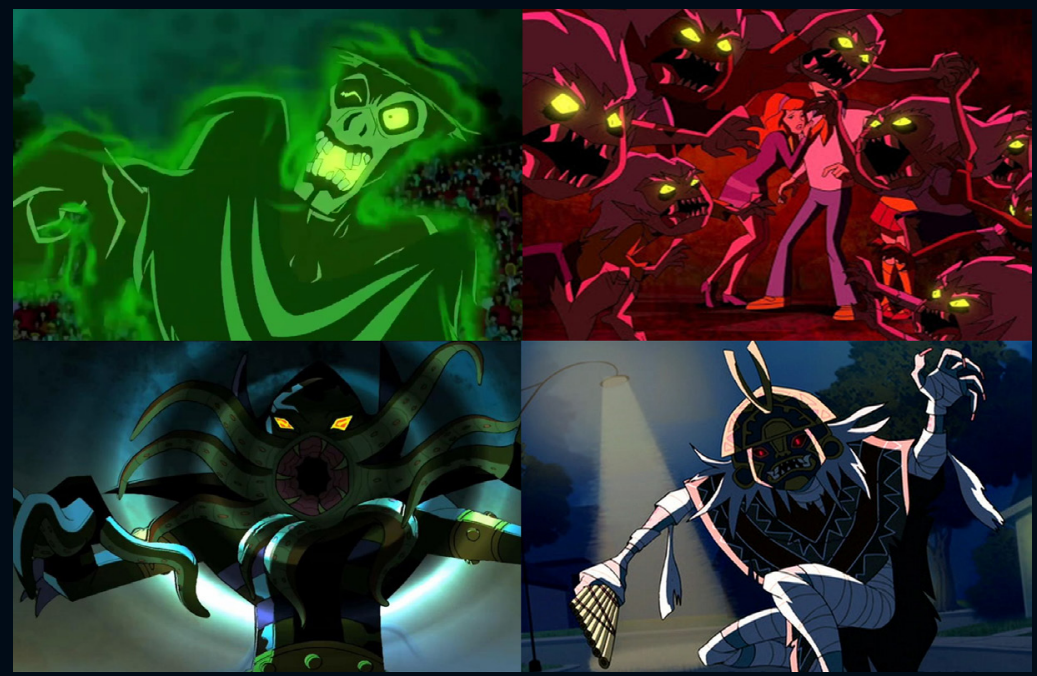

Figura 7

Cabe señalar que, aunque pueda parecer contradictorio cuando se recuerda la secularización finisecular de los imaginarios, en las ficciones de la franquicia se ha ido imponiendo lo sobrenatural sobre la razón. Se trata de un desplazamiento que se puede percibir con énfasis, cuando se mira algunas de las narraciones de las últimas décadas (tómese por caso la serie The 13 Ghosts of Scooby-Doo, 
1985, y la película Scooby-Doo on Zombie Island, 1998, en donde los monstruos no responden a fabulaciones, sino que, en efecto, son criaturas que quiebran las leyes de la naturaleza).

Con el paso de los años, esta inclinación se refuerza, y las historias del perro detective se han apartado de los artilugios criminales para brindarle margen a lo paranormal. Scooby-Doo! Mystery Incorporated no permanece exento, y aunque pueda pensarse que las explicaciones racionales (mutaciones genéticas, experimentos químicos, efectos tecnológicos) mitigan los misterios sobrenaturales que azotan a Cueva de Cristal, los males que acechan siempre destilan miedo: despiertan sentimientos de lo siniestro que, además, se sostienen mediante la truculencia del espaciotiempo representado y una banda sonora que compone toda una atmósfera de horror.

Interesa que, a medida que esta inclinación sobrenatural se intensifica, también lo hace la estructura del policial de misterio. Porque, detrás de cada encuentro paranormal, Scooby-Doo! Mystery Incorporated elabora una línea argumental continua que se construye progresivamente en estos episodios que, no en vano, se titulan "Chapters" (Capítulos). La serie animada toma, en todo su esplendor, forma de una serie televisiva, más cercana a la estructura de los dramas adultos que a los dibujos infantiles. Esta historia más profunda se centra en la "Maldición de la Gruta de Cristal": leyenda que esconde la búsqueda de un tesoro ancestral y un antiguo plan siniestro que involucra a los padres de la pandilla.

Consecuencia de esta trama oculta que los personajes prometen develar, la relación con los progenitores se invade de 
extrañeza y contradicciones: ante la pandilla detectivesca que recurre a la racionalidad de la ciencia y la tecnología para arrojar luz sobre los misterios, aparecen los adultos quienes, a toda costa, quieren creer en la existencia de los monstruos y otorgarles veracidad. Ello puede apreciarse claramente en la figura del alcalde (y padre de Fred) quien se impacienta por encontrar alguna entidad maléfica, puesto que "son buenas para el turismo" (T01 E08). Por lo cual, la serie introduce una crisis en la idealización de la autoridad familiar, al tiempo que expone su deterioro como un lugar de resguardo.

En su lugar, aparecen monstruos que los juzgan moralmente, como sucede con esa entidad que se define como una "amenaza puritana" y que castiga a jóvenes que se atreven a besarse lejos de la mirada paterna (T02 E09). No en vano, ante los destrozos que este monstruo provoca en su cacería, un personaje se interroga (y con cierta ironía): “¿cómo se supone que tomemos decisiones tontas y estúpidas que arruinen el resto de nuestras vidas con todo este ruido?" (T02 E09). Refuerza esta lectura el hecho de la pandilla, en detrimento de la primera versión, devengan justicieros paralegales, perseguidos constante por la policía local por intervenir en su jurisdicción.

Me atrevo a hipotetizar, por ello, que la primacía de lo sobrenatural puede explicarse, si se considera que este orden se presenta como un lugar, en cierto modo, confortable. Porque, en este relato, lo que se ha vuelto indiscernible es, precisamente, la misma realidad social, y el orden sobrenatural aparece, en su lugar, como una explicación incluso más tranquilizadora. Ante este mundo invadido por la incertidumbre, lo insólito, al decir de Campra, "da 
cuenta de algún grado de racionalidad o, por lo menos, de una irracionalidad codificada" (2008, p.137).

Como resultado, la narrativa escenifica un entorno en donde se asienta una imposibilidad de discernir claramente aquellos lindes que distancian el Bien del Mal. Dicho de otro modo, Scooby-Doo! Mystery Incorporated tiende a borrar estas divisiones mediante la composición de personajes repletos de claroscuros, en lo que supone un marcado desplazamiento en relación a la versión previa, pero un acercamiento a una característica sintomática de las series televisivas contemporáneas (JOST, 2015). Además del núcleo familiar, ello se percibe en quienes hacen uso de la monstruosidad para componer misterios. Pero, en esta narrativa, no involucran estafas, sino más bien una suerte de castigo por parte de otros adolescentes ignorados, vapuleados o discriminados. El desaire amoroso y el bullying sistemático son constantes que movilizan la venganza sobrenatural, retomando este motivo tan recurrente en el cine de terror actual ( $y$, por ello, el filme Carrie es una referencia insistente en este relato).

Scooby-Doo! Mystery Incorporated compone así un Beverly Hills, 90210 (1990-2000) en clave paranormal, que no cesa de interrogarse por la incertidumbre de una franja social que tampoco se termina de entender a sí misma. El profesor H.P. Hatecraft, personaje de aparición regular (y que parodia al reconocido escritor estadounidense), lo explica de una manera clara cuando, en su intento por escribir alguna de esas sagas de vampiros que se han vuelto tan exitosas, se pregunta cómo reinventarse artísticamente y captar un público juvenil más amplio, si los adolescentes se han vuelto todo un enigma. Quizá, por ello, el relato nos enfrente a un 
grupo de jóvenes que se obsesiona con resolver misterios porque, como bien interpela Vilma, repone una generación que "solo queremos respuestas, ¿̇eso está mal?" (T01 E01).

Concluyo esta lectura, preguntándome si la originalidad de Scooby-Doo! Mystery Incorporated no reside, casualmente, en haber traducido cierto desasosiego adolescente en un lenguaje juvenil y en formas ampliamente reconocibles, como son el misterio y el insólito sobrenatural. Avanza sobre el camino allanado por el relato original, pero complejiza esos engranajes de un insólito que, en palabras de Pampa Arán, "se expande en forma difícil de medir y que se transforma también [...] en síntoma de una asfixia subjetiva y cultural" (2019).

El relato explora las vicisitudes de su propia contemporaneidad, pues sabido es que la posmodernidad acarrea tensiones que afectan nuestra percepción de la cultura, como también cambios constitutivos en subjetividades que habitan, consecuencia del estallido del mundo digital y de los intempestivos avances tecnológicos y científicos, en una realidad cada vez más inaprensible y cuya materialidad parece volatilizarse (FISHER, 2009). Por estar sometidos a una existencia visual y plegarse al orden de la mirada, las entidades como fantasmas y monstruos facilitan su exorcismo (CAMPRA, 2008); lo que es difícil de conjurar, porque escapa a la aprehensión, es este malestar social que aparece como un signo epocal y que la narrativa ha querido reponer.

\section{CONCLUSIONES}

Como sucede en esas antologías en donde la contigüidad de los relatos termina por develar la naturaleza de los silencios (CAMPRA, 2008, p.131-132), el contraste Scooby-Doo, Where are 
you? y Scooby-Doo! Mystery Incorporated ha permitido apreciar variaciones históricas en la escenificación de lo extraño. En ambos casos, hay una preocupación latente por extrañar la cultura juvenil, en lo que puede asimilarse como un intento por revelar los avatares epocales de esta franja social. Y si la animación de 1969 se esmeró en proponer contrastes claros que permitieran diferenciar conjuntos de valores, la reciente producción arrostra la caída de los valores absolutos y un mundo donde las visiones maniqueas ya no son posibles. En efecto, ha hecho de lo extraño un lugar de enunciación desde donde lee entramados sociales y ejercita una crítica sobre lo que las culturas vivencian, pero también sobre lo que silencian.

En todas sus versiones, Scooby-Doo se presenta como una serie que mantiene siempre actualidad con su propio tiempo, recorriendo las corrientes culturales de su época. Su aparente banalidad puede leerse como negativa, pero el recorrido emprendido da habida cuenta de un gran potencial heurístico contenido. Su redundancia y su estereotipación se vuelven significativas pues, en su acumulación, sacan a superficie un intento por fijar ciertos efectos ideológicos. Ponen a prueba, además, el modo en que el curso de los años ha influido para que los temas clásicos del insólito, como sostiene la premisa de Pampa Arán, "se refinen intelectualmente" (2009, p.17). Y aunque, en sus derroteros más tardíos, esta primacía de lo sobrenatural pueda parecer discordante, los relatos estarían proponiendo su propia explicación: brinda un lugar tranquilizador ante las fracturas que se producen en las sociedades, como resultado de los vertiginosos cambios históricos que afectan nuestra percepción de lo real. Es 
esta, finalmente, la función semiótica del insólito, su vocación por materializar en el arte las transformaciones en la mentalidad cultural (ARÁN, 2009).

Pero conviene preguntarse, también, si esta intervención de lo sobrenatural no es resultado del mercado. No debe olvidarse que nos hallamos en un periodo donde las y los espectadores están avezados en el reconocimiento de los géneros, especialmente de aquellos donde la imposición de los estándares de mercado ha llevado a la pérdida de su regularidad, a su agotamiento y, en consecuencia, a su estereotipación. Sin embargo, las narrativas de Scooby-Doo demuestran que la saturación de las formas y los procedimientos del policial de misterio y el fantástico sobrenatural es, también, una característica productiva que no solo le permite al público moverse por un terreno cognoscible, sino que además fuerza a los géneros a su propia reinvención.

Por su cercanía, Scooby-Doo instaló un debate en torno a rasgos formantes de estas tradiciones, por lo demás recurrentes en las series televisivas actuales. Fecundó, en la memoria reciente, operaciones de sentido y una compleja mitología, materias primas para una cultura popular que puede perturbar lo conocido y volverlo novedad. Me pregunto si acaso, por su mutación incesante, lo extraño no puede pensarse en una variedad más amplia de relatos que se distancia del misterio y el fantástico sobrenatural, pero que sin embargo desafían la razón e instauran múltiples incertidumbres; textos que, finalmente, escenifican los temores y las ansiedades de nuestro tiempo, tratando de traducir eso para lo cual las culturas parecen carecer de palabras. 


\section{REFERENCIAS}

ALLEN, Robert (2001). "Introduction". In ALLEN, Robert (Ed). To Be Continued... Soap Operas around the World. New York: Routledge, p.1-26.

ARÁN, Pampa O. (1996). "Una interpretación ideológica de los géneros utópicos". Estudios, 6, 45-49.

ARÁN, Pampa O. (1999). El fantástico literario. Aportes teóricos. Córdoba: Narvaja Editor.

ARÁN, Pampa O. (2009). "Lo unido y lo enhebrado. Para una teoría del fantástico literario contemporáneo". In: VOLTA, Luigi y ELGUE-MARTINI, Cristina (Comps.). Fantasmas, sueños y utopías en literatura, cine y artes plásticas. Córdoba: El Copista. p.15-30.

ARÁN, Pampa O. (2019). "Gótico - elementos narrativos". In: REIS, Carlos; ROAS, David; FURTADO, Filipe; GARCÍA, Flavio; FRANÇA, Júlio (Eds.). Dicionário Digital do Insólito Ficcional (e-DDIF). Rio de Janeiro: Dialogarts. In http://www.insolitoficcional. uerj.br/site/g/gotico-elementos-narrativos Acceso em 25.Feb.2020.

BARTHES, Roland ([1957] 2010). Mitologías. Buenos Aires: Siglo XXI.

BIRD, Benjamin (2018). Scooby-Doo! Encyclopedia. Minnesota: Stone Arch Books. CAMPOS, Guadalupe (2010). "Déjà lu. La literatura fantástica, revisitada". Revista Luthor, 1(1), 29-36.

CAMPRA, Rosalba (2008). Territorios de la ficción. Lo fantástico. Sevilla: Editorial Renacimiento.

FISHER, Mark (2009). Realismo capitalista. ¿No hay alternativa? Buenos Aires: Caja Negra.

GÓMEZ PONCE, Ariel (2018). "A 20 años de Buffy, The Vampire Slayer. Notas sobre las series televisivas como un texto-código de la cultura". Revista Luthor, 37(8), 44-59.

GÓMEZ PONCE, Ariel (2020). "De series televisivas, intensidades y miedos posmodernos". En: Estudios, 43, 27-44.

JAMESON, Fredric (1989). Documentos de cultura, documentos de barbarie. La narrativa como acto socialmente simbólico. Madrid: Visor.

JAMESON, Fredric ([1992] 2007). Signaturas de lo visible. Buenos Aires: Prometeo. 
JAMESON, Fredric (2010). Bretch y el Método. Buenos Aires: Manantial.

JOST, François (2015). Los nuevos malos. Cuando las series desplazan las líneas del bien y del mal. Buenos Aires: Libraria.

LOTMAN, Yuri (2000). "Sobre el lenguaje de los dibujos animados". In: LOTMAN, Yuri. La semiosfera III. Semiótica de las artes y de la cultura. Madrid: Cátedra. p.138-143.

PERLMUTTER, David (2019). The Encyclopedia of American Animated Television Shows. New York: Rowman \& Littlefield.

SCOOBY-DOO, Where Are You? (1969-1970). RUBY, Joe; TAKAMOTO, Iwao; SPEARS, Ken (Creadores); HANNA, William; BARBERA, Joseph (Productores). Estados Unidos: Hanna-Barbera Productios / CBS.

SCOOBY-DOO! Mystery Incorporated (2010-2012). RUBY, Joe; TAKAMOTO, Iwao; SPEARS, Ken; SPEARS, Ken (Creadores); WATSON, Mitch; WYATT, Jason (Productor). Estados Unidos: Hanna-Barbera Productios / CBS.

SHKLOVSKI, Viktor ([1917] 2011). "El arte como artificio". In: TODOROV, Tzvetan (Comp.). Teoría de la literatura de los formalistas rusos. Buenos Aires: Siglo XXI. p.77-98.

TEOBALDI, Daniel Gustavo (2009). “Formas del misterio. El sentido de lo fantástico". In: VOLTA, Luigi y ELGUE-MARTINI, Cristina [Comps.]. Fantasmas, sueños y utopías en literatura, cine y artes plásticas. Córdoba: El Copista. p.67-85.

TODOROV, Tzvetan (1992). "Tipología del relato policial". In: LINK, Daniel (Comp.). El juego de los cautos. La literatura policial: de Poe al caso Giubileo. Buenos Aires: La Marca. p.46-76.

TODOROV, Tzvetan (1994). Introducción a la literatura fantástica. México: Ediciones Coyoacán. 